\title{
2016 update Japanese Society for Dialysis Therapy Standard of fluids for hemodialysis and related therapies
}

Michio Mineshima ${ }^{1,2,3^{*}}$, Hideki Kawanishi ${ }^{1,2}$, Tomonobu Ase ${ }^{1,2}$, Tadayuki Kawasaki ${ }^{1,2}$, Tadashi Tomo², Hidetomo Nakamoto ${ }^{2}$ and on behalf of the Subcommittee on the Function and Efficacy of Blood Purification Therapy, the Scientific Academic Committee of the Japanese Society for Dialysis Therapy

\begin{abstract}
The necessity of purification of dialysis fluids has been discussed since the 1980s. The Japanese Society for Dialysis Therapy (JSDT) presented a standard for dialysis fluid purification in 1995 and revised three times after that. Lastly, JSDT presented a new standard on microbiological management of fluids for Hemodialysis and related therapies in 2008 (the 2008 JSDT standard). It, however, specifies biological contaminants (ET and bacteria) alone.

The society further revised the 2008 JSDT standard with the addition of the water quality standard for chemical contaminants and management standard for water treatment equipment in 2016 (the 2016 JSDT standard). This article describes the 2016 JSDT.

Chapter 1 describes the water quality standard for biological contaminants without any modification of the standard values in the 2008 JSDT standard because the ultrapure dialysis fluid standard was met at $66.4 \%$ of all responder facilities in a 2014 survey conducted by the JSDT.

Chapter 2 describes the water quality standard for chemical contaminants. Twelve items are specified in the standard, inasmuch as the toxic potentials of these chemicals have been verified, or are suspected. When the water treatment equipment is operated appropriately, chemical contaminants are appropriately removed from raw water and safe dialysis water is supplied to dialysis machines. However, chemical contaminants in raw water should be confirmed at least before installation of the water treatment equipment. In the daily management, water quality data on the source of raw water must be confirmed in each season of the year. If some chemical contaminants in source of raw water do not meet the water quality standard, the relevant chemical contaminants in dialysis water should be measured at least once a year. Chapter 3 describes the measurement of the residual chlorine. The concentration of total residual chlorine (total chlorine) in dialysis water should be less than $0.1 \mathrm{mg} / \mathrm{L}$.

The management standard for water treatment equipment is proposed in Chapter 4. Chapter 5 describes in detail the management.
\end{abstract}

Keywords: Dialysis fluids, Water quality standard, Biological contaminants, Chemical contaminants, Water treatment equipment

\footnotetext{
* Correspondence: mmine@twmu.ac.jp

${ }^{1}$ Subcommittee on the Function and Efficacy of Blood Purification Therapy,

The Scientific Academic Committee of the Japanese Society for Dialysis

Therapy, Tokyo, Japan

${ }^{2}$ The Scientific Academic Committee of the Japanese Society for Dialysis

Therapy, Tokyo, Japan

Full list of author information is available at the end of the article
}

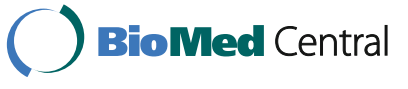

(c) Japanese Society for Dialysis Therapy. 2018 Open Access This article is distributed under the terms of the Creative Commons Attribution 4.0 International License (http://creativecommons.org/licenses/by/4.0/), which permits unrestricted use, distribution, and reproduction in any medium, provided you give appropriate credit to the original author(s) and the source, provide a link to the Creative Commons license, and indicate if changes were made. The Creative Commons Public Domain Dedication waiver (http://creativecommons.org/publicdomain/zero/1.0/) applies to the data made available in this article, unless otherwise stated. 


\section{Background and objectives}

The necessity of purification of dialysis fluids has been discussed since the 1980s, primarily in Europe. In Japan, the Japanese Society for Dialysis Therapy (JSDT) presented a standard for dialysis fluid purification [1] in 1995, and this standard was revised in 1998 [2] and 2005 [3], along with the spread of high-performance membrane dialyzers, online hemodiafiltration (HDF) therapy, etc. Nevertheless, the standard in Japan was revised solely in regard to the levels of endotoxins (ETs), and no precise standard was developed for bacteria. In various other countries, in contrast, a water quality standard with emphasis on the detection of bacteria has been presented and the International Organization for Standardization (ISO) has formulated the standard [4]. On the ground of the ISO standard, the JSDT presented a new Standard on Microbiological Management of Fluids for Hemodialysis and Related Therapies [5, 6] in 2008 (herein after, the 2008 JSDT standard) and Standard on the Management of Endotoxin Retentive Filter for Dialysis and Related Therapies [7] in 2011 (herein after, the 2011 JSDT ETRF standard). In concert with these standards, online HDF equipment and therapy became approved as a medical device and modality, respectively, covered by the national health insurance.

Following the institution of the 2008 JSDT standard, there was marked improvement in the degree of dialysis fluid purification at dialysis facilities across the country, and according to the JSDT statistical survey carried out at the end of 2014, ultrapure dialysis fluid standard had been achieved at $66.4 \%$ of all responder facilities [8]. Moreover, there has also been a marked increase in the patient population receiving online HDF therapy.

The 2008 JSDT standard, however, specifies biological contaminants (ET and bacteria) alone, with no specifications on chemical contaminants. Control of chemical contaminants is basically dependent on both the water quality of raw water and the performance of water treatment equipment. However, the water treatment equipment is not approved as a medical device in Japan. So no standard for the water treatment equipment has been set up, so that the onus has largely been left to the manufacturers of the equipment.

Under these circumstances, the Society further revised the 2008 JSDT Standard of Fluids for Hemodialysis and Related Therapies with the addition of the water quality standard for chemical contaminants and management standard for water treatment equipment. Thereby, it is expected that purification in whole process from dialysis water to final dialysis fluid can be achieved. As an additional remark, this document states that the scope of application of this standard is limited to blood purification (chronic/acute blood purification) undertaken at facilities.

\section{Chapter 1: water quality standard for biological contaminants}

1-1.Ultimate goals of the standard established for biological contamination

- Dialysis water Viable bacterial count: Less than $100 \mathrm{CFU} / \mathrm{mL}$ ET: Less than $0.050 \mathrm{EU} / \mathrm{mL}$

- Standard dialysis fluid Viable bacterial count: Less than $100 \mathrm{CFU} / \mathrm{mL}$ ET: Less than $0.050 \mathrm{EU} / \mathrm{mL}$

- Ultrapure dialysis fluid Viable bacterial count: Less than $0.1 \mathrm{CFU} / \mathrm{mL}$ ET: Less than $0.001 \mathrm{EU} / \mathrm{mL}$ (below the lower limit of the assay sensitivity)

Note: The action level of the above standard (degree of contamination requiring measures to prevent a tendency towards elevation of the contamination beyond the standard level) will be set in accordance with the contamination status of the facility, but typically at $50 \%$ of the maximum allowable level, except for the ET of ultrapure dialysis fluid.

- Online prepared substitution fluid

Sterile and non-pyrogenic (endotoxin-free)

1-2.Test for compliance

ET: Limulus lysate test. Any kit verified to have equivalent sensitivity might be used.

Detection of viable bacteria: Reasoner's agar no. 2 (R2A) and tryptone glucose extract agar (TGEA) plates should be basically used, although any other culture method proven to have equivalent assay sensitivity may be applicable, whatever the culture method employed or not.

Conditions of incubation: Plates should be incubated at $17-23{ }^{\circ} \mathrm{C}$ for 7 days insofar as R2A and TGEA are employed.

1-3.Sampling points

- Dialysis water: Outlet point of the water treatment equipment

- Dialysis fluid: Inlet of the dialyzer

- Online prepared substitution fluid: Substitution fluid sampling point

1-4.Day of sampling: Perform the sampling when the risk of contamination is expected to be the highest, hence leaving a maximum interval after the process of disinfection with chemical disinfectant/hot water, etc., in order to avoid overestimation of the water quality due to the effects of disinfection.

1-5.Frequency of monitoring (ET and viable bacteria)

- Dialysis water: Every 3 months (when the standard is being observed). At once a month unless the standard is met. 
- Standard dialysis fluid: At least one machine should be tested each month so that each machine is tested at least once a year.

- Ultrapure dialysis fluid: In the case of a dialysis machine which has been validated by a manufacturer, the standard for use of manufacturer should be observed. Dialysis fluid for preparing online substitution fluid should be tested for ET and viable bacteria at 2-week intervals until the system becomes stabilized. When the system is judged to have become stabilized by the Dialysis Equipment Safety Management Committee, at least one machine is tested each month so that each machine is tested at least once a year.

- Online prepared substitution fluid: Using a dialysis machine which has been validated by a manufacturer, the standard for use of manufacturer should be observed. Dialysis fluid for preparing online substitution fluid should meet the standard for ultrapure dialysis fluid. ET: Online prepared substitution fluid should be tested at 2-week intervals until the system becomes stabilized and at least once a month such that each unit is tested at least once a year after the system is judged to have become stabilized by the Dialysis Equipment Safety Management Committee. Viable bacteria: Assay at $10^{-6}$ is infeasible.

1-6.Conditions of dialysis to which the respective dialysis fluid standards are applicable

- Standard dialysis fluid
This fluid is of minimum quality for hemodialysis.

- Ultrapure dialysis fluid

Dialysis fluid for preparing online substitution

fluid

Dialysis machine positively using back filtration

dialysis fluid (e.g., fully automated dialysis machine)

Push-and-pull HDF machine

Internal filtration-enhanced hemodialysis

Recommended basically for all hemodialysis therapies

- Online prepared substitution fluid:

Online HDF/HF

1-7.Endotoxin retentive filter (ETRF) management standard

- For ETRF, refer to and aim to meet the 2011 JSDT ETRF standard [7].

1-8.Safety measures

Management of dialysis fluids and dialysis machines should be implemented in conformity with the guidelines laid down in the appropriate management manuals. Therefore, the medical device safety manager should perform validation of the dialysis machines at each facility. The manager will then carry out the following updates (Fig. 1).

1) Update the dialysis education and training curriculum.

2) Update the dialysis fluid management manuals.

3) Prepare a management record and assay record and retain these records in accordance with the method used for medical records. Relevant 
documents must be archived for 3 years from the date of preparation or for 1 year after the expiration date.

4) For management of dialysis machines and dialysis fluid water quality, the medical device safety manager will set up a Dialysis Equipment Safety Management Committee (DESMC) under the direction of the dialysis equipment safety manager and implement the following.

- The DESMC will draw up a plan for the management of dialysis machines, carry out appropriate conservation and management, and retain and manage reports.

- The DESMC will conduct training classes for each staff to ensure proper use.

- The DESMC will perform unified control of related medical care information and make it known to every user, without exception, and convey information on any accidents to the dialysis equipment safety manager.

5) Online prepared substitution fluid may be used solely in equipment that has been validated by the dialysis fluid manufacturer. Further, it should be used under a warrant of safety by the DESMC.

\section{Commentary}

After the publication of the JSDT 2008 standard $[5,6]$, the JSDT 2011 ETRF standard [7] was published. Thereafter, the online HDF apparatus was approved as a multi-purpose dialysis machine. Furthermore, a National Health Insurance reimbursement medical fee for online HDF and a dialysis fluid water quality-securing additional reimbursement fee were set. Thereby, the ultrapure dialysis fluid standard was met at $66.4 \%$ of all responder facilities in a 2014 survey conducted by the JSDT [8]. Also, according to a report from the Japanese Renal Data System, purification of dialysis fluid led to a decreased mortality rate [9]. These may be said to be the result of stipulations in the 2008 standard. The present revision is, therefore, limited to fine correction of the terms incorporating the above changes, without any modification of the standard values in respect of biological contamination. As for the theoretical background of the standard, please refer to the 2008 JSDT standard [5], the Letter to the Editor [6], stating the points of correction, and the 2011 JSDT ETRF standard [7].

\section{Chapter 2: water quality standard for chemical contaminants}

2-1.Chemical contaminants and relevant standards (Table 1)

\section{Commentary}

Typical disorders reflecting the impact of chemical contaminants include encephalopathy and osteomalacia caused by aluminum; hemolytic anemia induced by chloramine, copper, or zinc; and pruritus and ventricular fibrillation evoked by fluorine; other disorders caused by trace elements have also been reported. Under the Water Supply Act in Japan, 51 items are laid down as the water quality standard for drinking water. Furthermore, in ISO13959, 22 items are specified in the water quality standard for chemical contaminants in dialysis water (total chlorine, sulfates, potassium, antimony, barium, beryllium, silver, and thallium, in addition to some of the items stated in the water quality standard for drinking water) [10]. Strict control is required as to groups 1 and 2 in Table 1, inasmuch as the toxic potentials of these chemicals have been verified, or are suspected. As to group 3, however, the chemical contaminants are included herein on account of the US Environmental Protection Agency (EPA) Safe Drinking Water Act 1996, and these chemical contaminants are excluded from the measurement items in the 2016 Standard, because their toxicities in humans and the evidence for reference values have not been clearly documented even in ISO13959 and because most of these chemical contaminants are rejected sufficiently by an RO membrane.

2-2.Control of chemical contaminants: At installation of a water treatment equipment

1. Disclosed or measured values of source of raw water, which are provided from water supply utility or private water supply, should be confirmed.

2. Chemical contaminants in raw water should be measured and confirmed whether the measured values meet the water quality standard for drinking water.

3. Chemical contaminants in dialysis water should be measured and confirmed whether the measured values meet the water quality standard for chemical contaminants ${ }^{1}$.

4. In case some chemical contaminants in dialysis water do not meet the water quality standard for chemical contaminants, the water treatment equipment should be inspected and reconfigured to meet the water quality standard for chemical contaminants.

5. Even if chemical contaminants in dialysis water meet the water quality standard for chemical contaminants, the chemical contaminants in dialysis water should be measured about once a year, if some chemical contaminants in raw water ${ }^{2}$ do not meet the water quality standard for chemical contaminants. 
Table 1 The water quality standard for chemical contaminants in dialysis water (ISO13959) and the water quality standard for drinking water (the Water Supply Act in Japan)

\begin{tabular}{|c|c|c|c|c|}
\hline \multirow{2}{*}{$\frac{\text { Group }}{\text { Group } 1}$} & \multirow{2}{*}{$\begin{array}{l}\text { Category } \\
\text { Contaminants with documented } \\
\text { toxicity in hemodialysis }\end{array}$} & \multicolumn{3}{|c|}{ Maximum allowable levels (mg/L) } \\
\hline & & Chemical contaminants & ISO standard for dialysis water & $\begin{array}{l}\text { Water quality standard for } \\
\text { drinking water in Japan }\end{array}$ \\
\hline & & Aluminum & 0.01 & 0.2 \\
\hline & & Total chloride & 0.1 & No std. set \\
\hline & & Copper & 0.1 & 1 \\
\hline & & Fluorine compound & 0.2 & 0.8 \\
\hline & & Lead & 0.005 & 0.01 \\
\hline & & Nitrate (as N) & 2 & 10 \\
\hline & & Sulfate & 100 & No std. set \\
\hline & & Zinc & 0.1 & 1 \\
\hline \multirow[t]{4}{*}{ Group 2} & \multirow{4}{*}{$\begin{array}{l}\text { Electrolytes normally included in } \\
\text { dialysis fluid }\end{array}$} & Calcium & 2 & $300^{\mathrm{a}}$ \\
\hline & & Magnesium & 4 & \\
\hline & & Potassium & 8 & No std. set \\
\hline & & Sodium & 70 & 200 \\
\hline \multirow[t]{10}{*}{ Group 3} & Trace elements in dialysis water & Antimony & 0.006 & $0.02^{\mathrm{b}}$ \\
\hline & & Arsenic & 0.005 & 0.01 \\
\hline & & Barium & 0.1 & $0.7^{c}$ \\
\hline & & Beryllium & 0.0004 & No std. set \\
\hline & & Cadmium & 0.001 & 0.003 \\
\hline & & Chromium & 0.014 & 0.05 \\
\hline & & Mercury & 0.0002 & 0.0005 \\
\hline & & Selenium & 0.09 & 0.01 \\
\hline & & Silver & 0.005 & No std. set \\
\hline & & Thallium & 0.002 & No std. set \\
\hline
\end{tabular}

${ }^{a}$ Set down as total hardness

${ }^{\mathrm{b}}$ Complementary items

Items for further study

\section{Commentary}

When the water treatment equipment is operated appropriately, chemical contaminants are appropriately removed from raw water and safe dialysis water is supplied to dialysis machines. However, the contamination of raw water may be increased with the geographical region, season, and status (e.g., in the event of a disaster), so that such chemical contaminants may enter the patient's body. Therefore, it is necessary that the source of raw water be periodically confirmed.

Even if the source of raw water meets the water quality standard for drinking water, there still exists a risk of contamination by water piping systems, elevated tanks, etc. until the source of raw water arrives at the dialysis facility. It is important, therefore, to confirm that chemical contaminants in raw water meet the water quality standard for drinking water at least before installation of the water treatment equipment (the items and applicable standard are summarized in Table 2).
Measurement of chemical contaminants in dialysis water is mandatory after the water treatment equipment is installed. However, since it may require a few days until concentrations of the chemical contaminants can be determined, the water treatment equipment may be operated immediately after the installation as long as chemical contaminants in raw water meet the water quality standard for drinking water.

Concentrations of total residual chlorine, $\mathrm{Ca}^{2+}$, and $\mathrm{Mg}^{2+}$ in raw water obviously exceed the standard, but they are excluded, because their management standards are shown in Additional file 1: Table S1 "Management standard of water and device/unit".

\section{2-3.Control of chemical contaminants: Daily} management

When raw water is supplied under the "regulations based on the Water Supply Act in Japan" (see Additional file 2: Figure S2), 
Table 2 Water quality items and applicable standard at the time of installation of water treatment equipment

\begin{tabular}{|c|c|c|c|c|c|}
\hline Object & Water quality item & $\begin{array}{l}\text { To be determined } \\
\text { before installation }\end{array}$ & $\begin{array}{l}\text { To be determined } \\
\text { after installation }\end{array}$ & Remarks (applicable standard) & $\begin{array}{l}\text { Meeting the } \\
\text { requirements }\end{array}$ \\
\hline Source of raw water & $\begin{array}{l}51 \text { items (water quality standard for } \\
\text { drinking water in Japan) }\end{array}$ & 0 & - & $\begin{array}{l}\text { Water quality standard for } \\
\text { drinking water in Japan }\end{array}$ & Confirmed \\
\hline Raw water & $\begin{array}{l}12 \text { items (water quality standard for } \\
\text { chemical contaminants) }\end{array}$ & O & - & $\begin{array}{l}\text { Water quality standard for } \\
\text { drinking water in Japan }\end{array}$ & Measured \\
\hline Dialysis water & $\begin{array}{l}12 \text { items (water quality standard for } \\
\text { chemical contaminants) }\end{array}$ & - & O & $\begin{array}{l}\text { Water quality standard for } \\
\text { chemical contaminants }\end{array}$ & Measured \\
\hline
\end{tabular}

1) Water quality data on the source of raw water, which are provided from water supply utility or private water supply, must be confirmed in each season of the year.

2) If some chemical contaminants in source of raw water do not meet the water quality standard for chemical contaminants:

(1) Water quality data for chemical contaminants in source of raw water should be taken note of.

(2)In the case the Dialysis Equipment Safety Management Committee judges that there is possibility of contamination by chemical contaminants, the relevant chemical contaminants in dialysis water should be measured at least once a year.

(3) In the case that some chemical contaminants in dialysis water do not meet the water quality standard for chemical contaminants, the water treatment equipment must be inspected and reconfigured to meet the water quality standard for chemical contaminants under the responsibility of the Dialysis Equipment Safety Management Committee.

(4) Nitric acid and nitrites are typical chemical contaminants that are difficult to be rejected by the RO membrane.

When raw water is not supplied under the regulations based on the Water Supply Act in Japan (see Additional file 2: Figure S2),

1) Plan for water quality monitoring should be formulated in accordance with Water Supply Act in Japan, and the water quality monitoring should be performed appropriately according to the plan. Raw water shall meet the water quality standard for drinking water.

2) In the case that raw water meets the water quality standard for drinking water, raw water should be managed in the same method as "the raw water supplied in accordance with the regulation based on the Water Supply Act in Japan."

3) When raw water does not meet the water quality standard for drinking water (including cases where necessary items are not measured),
(1) Performance of the water treatment equipment should be reconfirmed, and chemical contaminants in both raw water and dialysis water should also be measured at least once a year.

(2) In case of some chemical contaminants in dialysis water do not meet the water quality standard for chemical contaminants, the water treatment equipment must be inspected and reconfigured to meet the water quality standard for chemical contaminants under the responsibility of the Dialysis Equipment Safety Management Committee.

\section{Commentary}

When raw water is supplied from "water supply utility," it is basically warranted for safety as drinking water and water quality data on the source of raw water are available to the public and updated on a regular basis, so the dialysis facilities can obtain and utilize these data for controlling chemical contamination in raw water.

However, chemical contaminants in source of raw water may not meet the water quality standard for chemical contaminants depending on the region, season, or other conditions. Strict control for raw water is required particularly, when some chemical contaminants in raw water are difficult to be rejected by $\mathrm{RO}$ membrane and are in a very high concentration. Therefore, it is recommended to measure the relevant chemical contaminants in dialysis water.

Nitric acid and nitrites may be mentioned concretely as potential contaminants. These chemical contaminants can cause methemoglobinemia in the body and consequent hypoxia. When the origin of raw water is underground water, some chemical contaminants in raw water may not meet the water quality standard for chemical contaminants in sporadic regions. Further, the rejection performance of $\mathrm{RO}$ membrane is low for nitric acid and nitrites, so that dialysis fluid may be contaminated by such chemical contaminants if management for the water treatment equipment is insufficient.

Furthermore, a warranty on compliance with the water quality standard based on the Water Supply Act in Japan is required at dialysis facilities when raw water is not 
supplied under the regulations based on the Water Supply Act in Japan, and if such warranty cannot be achieved, dialysis water must be strictly controlled against chemical contaminants.

2-4.Control of chemical contaminants: In the event of disasters or in case of emergencies

At the time of disasters or in case of emergencies, as source of raw water might be polluted, the water treatment equipment must be carried out under scrutiny and control, and it is desirable to measure chemical contaminants in both raw water and dialysis water as soon as the measurement becomes practicable after disasters or emergencies.

\section{Commentary}

At the time of disasters or in case of emergencies, water supply system including of source of raw water, water distribution network, and/or water service pipes in dialysis facilities might be damaged and chemical contaminants might be poorly controlled. Moreover, water utilities might increase residual chlorine concentration in finished water for preventing microbial contamination. Therefore, scrutiny and control of the water treatment equipment are necessary.

\section{Chapter 3: measurement of the residual chlorine}

1. It is recommended to measure the total residual chlorine (sum of free chlorine and combined chlorine [chloramine]).

2. The concentration of total residual chlorine (total chlorine) should be less than $0.1 \mathrm{mg} / \mathrm{L}$.

3. Management of the total residual chlorine should be carried out with reference to Additional file 1: Table S1: "Management standard of water and device/unit".

4. The concentration of total residual chlorine in raw water could increase at times of disasters or in case of emergencies; therefore, strengthening management of activated carbon after these incidents is of importance.

\section{Commentary}

Ammonia nitrogen may be contained in raw water, and it depends on the property of source of raw water. Ammonia nitrogen binds to free chlorine to form combined chlorine (chloramine). Contamination of dialysis fluid by the chloramine may be occurred, if the concentration of chloramine exceeds the treatment capacity of activated carbon or reverse osmosis membrane. Cases of hemolysis as a consequence have been reported [11]. On the 2016 standard, it is recommended to measure the total residual chlorine.

\section{Chapter 4: proposal of a "management standard for water treatment equipment"}

Raw water is treated by water treatment process such as filtration, ion exchange, adsorption, and reverse osmosis. After the treatment, dialysis water should meet both the water quality standard for chemical contaminants and water quality standard for biological contaminants.

Since there are a variety of devices available from many manufacturers, management of the water treatment equipment is left to each dialysis facilities. The 2016 JSDT standard, therefore, puts forth the proposal of "Management Standard for Water treatment Equipment" as a supplement.

In particular, Management Standard for Individual Component Units (Supplementary Chapter 4) is presented with the requirements for daily management. The Dialysis Equipment Safety Management Committee at each dialysis facility must conduct daily management with reference to the "Management Standard for Water Treatment Equipment."

\section{Chapter 5: supplement and management standard for water treatment equipment}

In Japan, water treatment equipment is not classified under the category of medical devices, and each manufacturer establishes their original standards and conduct production control and quality control. There is also no overt management standard in respect of maintenance, and each dialysis facilities have managed the water treatment equipment by themselves, in accordance with the manufacturer's standards for maintenance and inspection, etc. In light of the current situation, the Japanese Society for Dialysis Therapy has set up a management standard for water treatment equipment to ensure preparation of safe and stable dialysis water.

\section{Supplementary Chapter 1 overview}

\section{1-1.Purpose}

The purpose of this management standard is to constantly ensure fulfillment of the requirements for dialysis water indicated in the 2016 JSDT standard. In order to achieve this purpose, this standard presents to manufacturers of water treatment equipment the performance that water treatment equipment must be endowed with at the time of shipment.

Dialysis water prepared by water treatment equipment is used as a diluent for dialysis fluid; therefore, removal and management for chemical contaminants, as well as of biological contaminants, is highly required. Occurrence of chemical contaminants, mainly metallic elements, in dialysis water brings about various harmful effects in vivo, and if biological contaminants represented by 
endotoxins enter the blood, they cause many adverse reactions such as fever, inflammation, and depressed hemopoiesis.

1-2.Scope

This management standard applies to water treatment equipment which is composed of a pretreatment unit, an $\mathrm{RO}$ unit, and an RO permeate supply unit. The pretreatment unit includes such devices as cartridge filter, softener, and activated carbon (Additional file 3: Figure S1) [12].

1-3.Performance

- Supplies the flow rate of dialysis water necessary for dialysis therapy

- Meets the water quality standard for dialysis water 1-4.Exclusion of application

Water treatment equipment excluded from this standard should conform to the management standard of the manufacturers of the water treatment equipment.

\section{Commentary}

Water treatment equipment is not classified under the category of medical devices in Japan but is a device that is indispensable to dialysis therapy, as it is aimed at protection of hemodialysis patients from adverse reactions that arise from chemical contamination and biological contamination of water origin. Manufacturers of water treatment equipment in Japan have thus been pursuing product development keeping in mind not only enhanced efficiency of the water treatment technique, but also improvement of the purification level constantly. Management of both daily operation and periodic maintenance are important to maintain the level of purification highly. Management of daily operation is aimed at an accurate grasp of the conditions of the devices, while management of maintenance is to prevent occurrence of mechanical faults and malfunctions. Devices required management of both daily operation and maintenance in water treatment equipment include softener, activated carbon, RO membrane, ultraviolet irradiator, UF membrane, various monitoring equipment, and pumps. Management of both daily operation and periodic maintenance should be conducted by the dialysis facility and will lessen unexpected faults and contribute to stable operation of the equipment.

Water treatment equipment has been developed for the purpose of separating and removing undesired substances with the principles of filtration, adsorption, and membrane separation. In the performance evaluation of the equipment, it is important to take into account not only the separating and removing capacity, but also the durability of the equipment.
Additional file 3: Figure S1 depicts an example of standard specification water treatment equipment. Options include raw water supply unit and ultrafiltration unit.

For water treatment equipment falling under exclusion, the manufacturers of water treatment equipment should establish individual management standards in accordance with this management standard.

\section{Supplementary Chapter 2: definition of terms}

(1) Terms relating to water (see Additional file 3: Figure S1)

- Raw water ...... Water flowing into a raw water supply unit of the water treatment equipment, or water flowing directly into a pretreatment unit

- RO feed water ...... Water flowing into an RO unit (flow rate of $\mathrm{RO}$ feed water = flow rate of $\mathrm{RO}$ permeate + flow rate of $\mathrm{RO}$ retentate)

- RO permeate ...... Water purified by an RO unit

- RO retentate ...... Concentrated water discharged from an RO unit

- Dialysis water ...... Water in the outlet point of the water treatment equipment, which supplies to the central dialysis fluid delivery system or individual dialysis fluid delivery system

- Source of raw water ......Water provided by water supply utilities or private water supply, ensuring its quality

(2) Terms relating to the water quality/standard

- Conductivity ...... An indicator of a substance's ability to conduct an electrical current; the fewer the substance contains electrolytes, the smaller is the value of this indicator. Synonyms: electrical conductivity, electrical conductance, and conductance.

- Water quality standard of chemical contaminants, Water quality standard of biological contaminants ...... Water quality standards for dialysis water specified in the 2016 JSDT standards

- RO rejection performance ...... The performance is evaluated by rejection coefficient of conductivity of the RO unit or conductivity in $\mathrm{RO}$ permeate in this management standard

(3) Terms relating to equipment

- RO unit ...... A unit composed of RO membranes, a high-pressure pump, etc.

- Water treatment equipment ...... Equipment made up of a pretreatment unit, an RO unit, and an RO permeate supply unit, and options include a raw water supply unit and a ultrafiltration unit

(4) Terms relating to operational procedures

- Cleaning ...... The act of removing foreign substances (e.g., contaminants, organic substances) from an object 
- Disinfection ...... The process of eliminating infection risk by inactivation or removing all, or most part of pathogenic microorganisms (except for bacterial spores) from an object. The term does not necessarily mean extermination of microorganisms.

- Validation ...... The procedure to ensure appropriate performance by appropriate daily management and maintenance management

- Recovery rate ...... The proportion of RO permeate to RO feed water, calculated by the flow rate of $\mathrm{RO}$ permeate and that of $\mathrm{RO}$ feed water (RO permeate $+\mathrm{RO}$ retentate)

- Production operation ...... The process of producing a specific flow rate of $\mathrm{RO}$ permeate with an RO unit. Synonyms: water production operation, purification operation

(5) Terms relating to water supply system

- Water supply utility ...... A utility that provides water via water supply system to meet the public demands, except for utilities serving populations of 100 or less (Water Supply Act, Article 3, Paragraph 2)

- Private water supply ...... Water supply systems for private use, such as dormitories, company housings, clinics, etc., and other systems excluding bulk water supply utilities, which meet either of the following requirements:

- Water supply systems providing residential water for more than 100 persons

- Water supply systems providing domestic water of more than $20 \mathrm{~m}^{3}$ per day

- Public water supply utility ...... "Water supply utility" or "Bulk water supply utility." "Private water supply" is not included.

\section{Supplementary Chapter 3: water quality standard and water supply utility}

3.1.Water quality management for dialysis water using validated equipment

Water quality management of dialysis water should be conducted with validated water treatment equipment.

\section{Commentary}

A dialysis facility has an aspect of an on-site dialysis fluid manufactory and is responsible for the quality of dialysis fluid as final products. Dialysis water plays an important role in the preparation of dialysis fluid. Therefore, appropriate daily management and maintenance management of water treatment equipment are crucial, and the management standards are required for implementing this. Each dialysis facility should prepare dialysis water using validated preparation equipment and control its quality and quantity.

\subsection{Water quality standards for raw water}

Raw water to be used for the preparation of dialysis water shall meet the water quality standards based on the Water Supply Act (Law No. 177, 1957), no matter which sources the raw water comes from, e.g., municipal water or groundwater.

\section{Commentary}

Raw water to be used for dialysis water should meet the water quality standards based on the Water Supply Act. There are three types of water supply systems within the regulatory framework under the Water Supply Act, i.e., "water supply utility," "bulk water supply utility," and "private water supply" (Additional file 2: Figure S2) [13].

When the raw water is provided by the "water utility," the fulfillment of the water quality standards has already been confirmed by the water utility, so further water quality management by the dialysis facility is not necessary. Also, when the raw water is provided by a "private water supply," the fulfillment of the water quality standards has already been confirmed based on the Enforcement Regulations for the Water Supply Act, so further water quality management by the dialysis facility is not necessary. On the other hand, when raw water is provided by water supply systems not subject to the regulations based on the Water Supply Act, water quality management is mandatory by the dialysis facility.

It is desirable to use raw water provided by the water supply utility for preparing dialysis water.

\subsection{Monitoring of water quality}

\subsubsection{Sample points}

It should be sampled for raw water, $\mathrm{RO}$ feed water, $\mathrm{RO}$ permeate, and dialysis water.

- Raw water: Water flowing into a raw water supply unit of the water treatment equipment or water flowing directly into a pretreatment unit.

- RO feed water: Water flowing into an RO unit.

- RO permeate: Water purified by an RO membrane.

- Dialysis water: Water in the outlet point of the water treatment equipment, which supplies to the central dialysis fluid delivery system or individual dialysis fluid delivery system.

\subsubsection{Measurement}

- Raw water: Chemical contaminants should be measured.

- $\mathrm{RO}$ feed water: Conductivity should be measured using a conductivity monitor (when 
controlled in terms of the rejection coefficient of conductivity).

- RO permeate: Conductivity should be measured using a conductivity monitor.

- Dialysis water: Biological contaminants and chemical contaminants should be measured.

\section{Commentary}

Additional file 3: Figure S1 illustrates the sampling points of $\mathrm{RO}$ feed water, $\mathrm{RO}$ permeate, and dialysis water.

For the cases of RO feed water and RO permeate, conductivity should be measured using a conductivity monitor, which are on-line method or off-line method by sampling. RO permeate should be measured when the water treatment equipment is production operation.

Dialysis water should meet both the water quality standard for biological contaminants and chemical contaminants.

The sampling point of dialysis water must be confirmed with the manufacturers of the water treatment equipment. For the frequency of monitoring, see Additional file 1: Table S1.

\section{Supplementary Chapter 4: management standard for individual component units (Additional file 1: Table S1)}

\subsection{Pretreatment unit}

4.1.1.Cartridge filter

This device is a filter to protect the pumps and RO membrane from malfunctioning due to coarse particle in raw water or RO feed water. It is also referred to as a pre- or check filter.

The life of cartridge filter is managed in terms of the pressure loss, pressure, or flow rate. The standard value should be laid down in terms of the pressure or flow rate, and any cartridge filter for which these parameters exceed the standard value should be replaced. Replacement of cartridge filter should be in conformity with the manufacturer's recommendation; usually, replacement is carried out at roughly 3-month intervals.

\subsubsection{Softener}

Softener is used to remove the hardness (mainly, $\mathrm{Ca}^{2+}$ and $\mathrm{Mg}^{2+}$ ) in raw water by ion exchange using a cation exchange resin packed in a cylinder. It is installed for the purpose of maintaining the $\mathrm{RO}$ membrane performance for a long time.

It is procedurally simple to use a hardness indicator to check raw water for leakage of hardness. When a few drops of the indicator is added to water treated by softener, the sample assumes a blue color if it is soft water, while the sample shows a red pink color if there is a leakage of hardness. The hardness should be measured in the exit of softener, and the results should be recorded in an operation diary on the day of dialysis therapy. Furthermore, it should also be checked that the ion exchange resin is functioning normally after replacement of the ion exchange resin.

Any other simple methods except hardness indicators may also be acceptable. However, the methods should be consistent with hardness indicators. Periodically replenish brine tank with regenerating salt. Check the presence of undissolved salt in the brine tank. Replacement of the resin should be in conformity with the manufacturer's recommendation; usually, the replacement is carried out at approximately 2-year intervals.

4.1.3. Activated carbon

This equipment is designed to remove free chlorine, chloramine, and organic substances contained in raw water that account for early deterioration of the RO membrane, by means of activated carbon packed in a cylinder. It is installed for the purpose of maintaining the RO membrane performance for a long time. Carbon cartridge filter type endowed with a filtering function has become widely popular in recent years.

\subsubsection{Requirements}

Chlorine should be measured as the total residual chlorine (i.e., sum of free chlorine and chloramine). The concentration of the total residual chlorine should be less than $0.1 \mathrm{mg} / \mathrm{L}$ in exit of an activated carbon, and the total residual chlorine should be measured by the $N$, $N$-diethyl- $p$-phenylenediamine (DPD) method. On-line monitoring may also be used, in which case, it should definitely be in accordance with the manufacturer's manual, and maintenance (incl. calibration) is necessary. The chlorine in dialysis water should be measured as the total residual chlorine, and the measurement should be conducted on the day of dialysis therapy. In the case where raw water is also measured and found to show total residual chlorine of $\geq 1 \mathrm{mg} / \mathrm{L}$, the frequency of measurement of the dialysis water should be changed to "at each session of dialysis therapy." The measurement for the total residual chlorine should be performed quickly on the spot in order to prevent a progressive decline of the total residual chlorine over time. The total residual chlorine in exit of the activated 
carbon should be determined, and the results should be recorded in an operation diary. If total residual chlorine of $\geq 0.1 \mathrm{mg} / \mathrm{L}$ is found, replacement of the activated carbon should be considered. After the replacement, it should be ascertained that the activated carbon is functioning normally.

4.1.3.2. Carbon adsorption bed type

The system is composed of an airtight cylindrical container, valves for backwashing and washing, and accessories for equipment control (flow meter, pressure gauge). Activated carbon is packed in a cylindrical container, with a supporting structure or strainer underneath to prevent carbon outflow. If activated carbon is used over many hours, raw water-derived solids and slime are accumulated in the upper layer of the activated carbon, leading to an increase of pressure loss. Therefore, cyclic backwashing should be conducted to discharge these substances out of activated carbon. Replacement of the activated carbon should be in conformity with the manufacturer's recommendation; usually, the replacement is carried out at roughly 2-year intervals.

4.1.3.3.Carbon cartridge filter type A carbon cartridge filter type is fitted into a stainless or plastic container and the cartridge is periodically replaced with a fresh one. This system is characterized by its being of a small size and readily replaceable. As it has a concurrent role of functioning as a filter, however, the cartridge may have to be replaced in the case of clogging, even if the chlorine is removed properly. Nevertheless, maintenance should be thorough, because, conversely, of an extremely short duration of contact.

Replacement of cartridge should be in conformity with the manufacturer's recommendation; usually, the replacement is carried out at roughly 3-month intervals.

\subsection{Reverse osmosis ( $\mathrm{RO}$ ) unit}

This unit almost completely rejects electrolytes, organic compounds, ET, etc., contained in the water supplied to the RO membrane by the principle of reverse osmosis. By applying a high pressure greater than the osmotic pressure of the supplied water ( $\mathrm{RO}$ feed water) on the primary side of the $\mathrm{RO}$ membrane, highly purified $\mathrm{RO}$ permeate flows from the secondary side of the RO membrane. Reverse osmosis is a membrane separation process that allows removal of the smallest substances; it is used in desalination technology for seawater, etc., and is indispensable for the water treatment equipment.
Replacement of the RO membrane should be in conformity with the manufacturer's recommendation; usually, the replacement is carried out at roughly 3-year intervals.

The RO unit is managed in terms of the following two parameters.

(1) RO rejection performance

The following two criteria are set down as the management standard for the $\mathrm{RO}$ rejection performance; either criterion should be fulfilled.

- Rejection coefficient of conductivity in the RO unit ....... Not less than 93\%

- Conductivity of the RO permeate ...... Not more than $25 \mu \mathrm{S} / \mathrm{cm}$ (temperature compensated to $25^{\circ} \mathrm{C}$ )

(2) Flow rate of $\mathrm{RO}$ permeate Flow rate of RO permeate should satisfy the flow rate required for hemodialysis and related therapies and the preparation.

4.3. RO permeate supply unit

4.3.1.Storage tank for $\mathrm{RO}$ permeate

The storage tank is installed as a reservoir for $\mathrm{RO}$ permeate. It is recommended that the tank has an airtight structure to prevent internal contamination. Each ventilation site should be fitted with a 0.1 to $0.45 \mu \mathrm{m}$, hydrophobic, disinfectant air filter to cope with changes in the water level.

Replacement of the air filter should be in conformity with the manufacturer's recommendation; usually, the replacement is carried out at roughly 1-year intervals.

4.3.2. Ultraviolet irradiator

Ultraviolet irradiator is available as the inline type or the immersion type. It is a common practice to install an immersion-type device within a storage tank of RO permeate of water treatment equipment. In the case of use of the immersion type, irradiation with 254-nm ultraviolet rays is carried out inside the RO permeate tank to sterilize the RO permeate that flows into the tank. An ultraviolet germicidal lamp generally has an approximate lifetime of 1 year when lit continuously. As the lifetime varies with individual lamps, the lifetime recommended by the manufacturer must be taken note of for timely replacement of the lamp.

\section{Commentary}

As concrete numerical values are specified in the management standard of activated carbon in ISO23500 [4], these specifications should be followed.

Free chlorine causes deterioration of the RO membrane, as mentioned below, and it is possible that contamination 
of dialysis fluid with chloramine causes hemolytic accidents. Therefore, management of the total residual chlorine (sum of free chlorine and chloramine) is of great importance. In case that the chloramine in raw water is $\geq 1 \mathrm{mg} / \mathrm{L}$, two-stage series installation of activated carbon should be undertaken to remove the chloramine.

Since there is no concrete management standard in respect of the $\mathrm{RO}$ rejection performance, the management standard has newly been established based on the present situation in Japan.

It has been established that the "rejection coefficient of conductivity in the RO unit", as a parameter of the RO rejection performance, should not be less than $93 \%$. This has been cited from the sodium chloride rejection performance of RO membrane stipulated in the "AMST002 Standards for reverse osmosis module and nanofiltration membrane module for drinking water use" in the "Provisions for Certification of Modules for Drinking Water Use" established down by the Association of Membrane Separation Technology of Japan [14]. "A rejection coefficient of conductivity is not less than 93\%," being the management standard for the RO rejection performance, may be interpreted as representing a "total solids (TS) or total dissolved solids (TDS) established rate of not less than 93\%."

TS, and TDS ...... The former means substances left after evaporation of the sample water, while the latter means substances left after evaporation of the filtrated sample. Hence, TS $=$ suspended solids (SS) + TDS. As little or no suspended solids is present in raw water, the relational expression would be TS = TDS in the case of raw water. There is a correlation between the conductivity and TDS.

The ISO26722 [15] states that "trace elements in dialysis water" can be met the water quality standard of chemical contaminants by using both water that can be met the water quality standard for drinking water in Japan and a reverse osmosis system with a rejection of $>90 \%$ based on conductivity, resistivity, or TDS.

The rejection coefficient of conductivity in the RO unit can be calculated using the following equation based upon measurement of the conductivities of $\mathrm{RO}$ feed water and RO permeate.

$$
R=\frac{C_{1}-C_{2}}{C_{1}} \times 100
$$

$R$ : Rejection coefficient of conductivity in the RO unit (\%) $C_{1}$ : Conductivity of RO feed water $(\mu \mathrm{S} / \mathrm{cm})$

$C_{2}$ : Conductivity of RO permeate $(\mu \mathrm{S} / \mathrm{cm})$

It has been specified that the "conductivity of RO permeate," another management standard of the RO rejection performance, should not be more than $25 \mu \mathrm{S} / \mathrm{cm}$.
This was specified from the concentration distribution data of TDS of faucet water on the drinking water database of the Japan Water Works Association and the rejection coefficient of conductivity of $93 \%$. The alert level of conductivity of RO permeate shall be $50 \%$ of the management standard $(12.5 \mu \mathrm{S} / \mathrm{cm})$.

The rationale for why conductivity is used as the management standard for the $\mathrm{RO}$ rejection performance is that a water treatment system is usually equipped with a conductivity monitor, which is used for performance management of RO membranes. The conductivity monitor should be checked and calibrated or replaced at 1 -year intervals. Though different from the water quality standard for dialysis water, the conductivity monitor is used for daily management of the water quality monitoring in the production of water for injection.

The reasons why rejection coefficient of conductivity and conductivity of RO permeate have been adopted as the standards for the $\mathrm{RO}$ rejection performance, where either parameter of the standard should be fulfilled, are as follows:

1) When conductivity of RO feed water is low, the rejection coefficient of conductivity usually tends to be low, as a characteristic of the RO membrane.

2) As a recent trend of water treatment equipment, high recovery rate for operations has become widespread, because the usage of raw water can be decreased by high recovery rate, so that the conductivity of RO permeate may be raised.

The recovery rate of the $\mathrm{RO}$ unit should be calculated from the following formula, based on measurement of the flow rate of $\mathrm{RO}$ permeate and $\mathrm{RO}$ retentate.

$$
Y=\frac{Q_{p}}{Q_{p}+Q_{r}} \times 100,
$$

where $Y$ is the recovery rate $(\%), Q_{p}$ the flow rate of the $R O$ permeate, and $Q_{r}$ the flow rate of the $R O$ retentate.

or,

$$
Y=\frac{Q_{\mathrm{p}}}{Q_{\mathrm{f}}} \times 100,
$$

where $Q_{\mathrm{f}}$ is the flow rate of $\mathrm{RO}$ feed water.

As for the flow rate of $\mathrm{RO}$ permeate, a flow rate of water required for dialysis therapy and its preparation must be secured. However, the flow rate of RO permeate is not equal to the flow rate of dialysis water supplied to the dialysis machine from the water treatment equipment. Also, when a large flow rate is required temporarily, RO permeate stored in a storage tank may be used. 
$\mathrm{RO}$ permeate is water-treated by the $\mathrm{RO}$ membrane which is capable of rejecting even the smallest substances; however, this process cannot provide complete rejection of bacteria or ET owing to the structure of $\mathrm{RO}$ element and manufacturing methods of RO element. Eventually, a UF membrane more suited to rejecting of bacteria and ET may be installed to obtain dialysis water of a higher purification level. UF membrane is installed at the exit of the storage tank of RO permeate or at the return port of dialysis water, to reject bacteria and ET and prevent secondary contamination in storage tank of RO permeate. Periodic disinfection is necessary, together with piping for supplying $\mathrm{RO}$ permeate, in order to prevent the UF membrane from becoming a source of contamination. The UF membrane should be managed in terms of the pressure or flow rate, viable bacterial count, and ET level, and it is effective to sample water at the inlet of the UF membrane to check the degree of biological contamination.

\section{Supplementary Chapter 5: cleaning and disinfection Cleaning and disinfection}

Cleaning and disinfection of the water treatment equipment should be carried out using the method of cleaning and disinfection recommended by the manufacturer of the water treatment equipment.

\section{Commentary}

The water treatment equipment should be periodically cleaned (washed) and disinfected to maintain its performance and purification.

Methods of cleaning and disinfection recommended by the manufacturers should be followed, since the methods used for cleaning and disinfection of the water treatment equipment (e.g., concentration, temperature, time, frequency) affect the performance and durability of the equipment. In case methods other than the methods of cleaning and disinfection recommended by the water treatment equipment manufacturers are selected, the Dialysis Equipment Safety Management Committee should assume responsibility.

\section{Conclusions}

The Japanese Society for Dialysis Therapy updated the dialysis therapy standard of fluids for hemodialysis and related therapies with the addition of the water quality standard for chemical contaminants and management standard for water treatment equipment in 2016. Thereby, it is expected that purification in whole process from dialysis water to final dialysis fluid can be achieved.

\section{Endnotes}

${ }^{1}$ The water treatment equipment may be operated under the judgment of the Dialysis Equipment Safety
Management Committee even immediately after the water treatment equipment is installed, because it may require a few days until the concentration of chemical contaminants can be determined.

${ }^{2}$ Chemical contaminants of which management standard included in the "Management Standard of water and device/unit" in Additional file 1: Table S1 are excluded.

\section{Additional files}

Additional file 1: Table S1. Management standard of water and device/unit. (DOCX $21 \mathrm{~kb}$ )

Additional file 2: Figure S2. Distribution of water supply utilities and private water supply. Source (with partial modifications): Japan Water Plumbing Engineering Promotion Foundation (2013) "Guideline for Water Supply Equipment Plumbing Engineering," Revised Edition, p. 12 [13]. (PPTX $78 \mathrm{~kb}$ )

Additional file 3: Figure S1. Flowchart of water treatment equipment-example. (Cited from Guidebook for dialysis water [12], with partial modification) (PPTX $95 \mathrm{~kb}$ )

\section{Acknowledgements}

The authors thank the committee members and the concerned persons who took part in formulating the 2016 Japanese Society for Dialysis Therapy Standard.

Funding

Not applicable

Availability of data and materials Not applicable

\section{Authors' contributions}

MM generalized the manuscript as chairman of the Subcommittee on the Function and Efficacy of Blood Purification Therapy, the Scientific Academic Committee of the Japanese Society for Dialysis Therapy. HK generalized the manuscript as member of the Subcommittee on the Function and Efficacy of Blood Purification Therapy, the Scientific Academic Committee of the Japanese Society for Dialysis Therapy. TA was in charge of the supplementary chapters and generalized the manuscript as member of the Subcommittee on the Function and Efficacy of Blood Purification Therapy, the Scientific Academic Committee of the Japanese Society for Dialysis Therapy. TK contributed as member of the Subcommittee on the Function and Efficacy of Blood Purification Therapy, the Scientific Academic Committee of the Japanese Society for Dialysis Therapy. TT contributed as chairman of the Scientific Academic Committee of the Japanese Society for Dialysis Therapy. HN contributed as Chief Director of the Japanese Society for Dialysis Therapy. All authors read and approved the final manuscript.

Ethics approval and consent to participate Not applicable

Consent for publication

This manuscript does not contain any data relating to individuals.

\section{Competing interests}

The authors declare the following conflicts of interest: Michio Mineshima has been receiving technical advisory fees, honoraria, and grants-in-aid for research from JMS Co., Ltd. (a company that manufactures, markets, imports and exports medical devices and pharmaceuticals), and Nipro Co., Ltd. (a company that conducts R\&D of medical devices and pharmaceuticals).

Hideki Kawanishi has been receiving honoraria from Chugai Pharmaceutical Co., Ltd. (a company that manufactures, markets, imports, and exports ethical drugs), Kyowa Hakko Kirin Co., Ltd. (a company that manufactures and markets ethical drugs), and Bayer Yakuhin, Ltd. (a company that develops, 
imports, manufactures, and markets pharmaceuticals, medical devices, and drugs for animals).

Tomonobu Ase has been receiving salary as a company employee of Daicen-Membrane Systems Ltd., has participated in formulating the management standard for water treatment equipment as a representative of the Committee on Dialysis water of the Association of Membrane Separation Technology of Japan and as an external member of this subcommittee.

Hidetomo Nakamoto has been receiving honoraria and grants-in-aid for scientific research from Toray Industries, Inc. (a company that manufactures and markets pharmaceutical and medical care products), Astellas Pharma Inc. (a company that manufactures, markets, exports, and imports pharmaceutical products), Baxter Limited (a company that imports, manufactures, and markets dialysis products, plasma protein preparations, and drug delivery systems), Chugai Pharmaceutical Co., Ltd. (a company that manufactures, markets, imports, and exports ethical drugs), Kyowa Hakko Kirin Co., Ltd. (a company manufacturing and marketing ethical drugs), Terumo Corporation (a company that manufactures and markets medical devices and pharmaceuticals), Kissei Pharmaceutical Co., Ltd. (a company that conducts R\&D and manufactures and markets ethical drugs), Chugai Pharmaceutical Co., Ltd. (a company that manufactures, markets, imports, and exports ethical drugs), Sumitomo Dainippon Pharma Co., Ltd. (a company that manufactures and markets ethical drugs, diagnostic drugs, etc.), and Takeda Pharmaceutical Company Limited (a company that manufactures, markets, imports, and exports pharmaceutical products, quasi drugs, etc.).

The other authors declare that they have no competing interests.

\section{Author details}

'Subcommittee on the Function and Efficacy of Blood Purification Therapy, The Scientific Academic Committee of the Japanese Society for Dialysis Therapy, Tokyo, Japan. ${ }^{2}$ The Scientific Academic Committee of the Japanese Society for Dialysis Therapy, Tokyo, Japan. ${ }^{3}$ Department of Clinical Engineering, Tokyo Women's Medical University, 8-1, Kawada, Shinjuku-ku, Tokyo 162-8666, Japan.

Received: 13 December 2017 Accepted: 13 February 2018 Published online: 21 March 2018

\section{References}

1. Yamagami S. Report on formulation of the dialysis fluid safety standard. J Jpn Soc Dial Ther. 1995;28:1487-93.

2. Morii H, Asano Y, Naito H, Takezawa S. On dialysis fluid safety standard and facility standard for Gambro AK100-Ultra. J Jpn Soc Dial Ther. 1998;31:1107-9.

3. Kawanishi H, Mineshima M, Takezawa S, et al. New water quality standard for dialysis fluid and functional classification of blood purification system. J Jpn Soc Dial Ther. 2005;38:149-54

4. ISO 23500: 2014, Guidance for the preparation and quality management of fluids for haemodialysis and related therapies. http://www.iso.org/iso/

5. Akiba T, Kawanishi H, Mineshima M, et al. Water quality standard for dialysis fluid and blood purification system performance assessment standard 2008. J Jpn Soc Dial Ther. 2008;41:159-67.

6. Akiba T, Kawanishi H. Supplementary article for the reference [5]. J Jpn Soc Dial Ther. 2008;41:457-9.

7. Kawanishi H, Masakane I, Mineshima M, et al. 2011 Japanese Society for Dialysis Therapy Standard on Management of Endotoxin Retentive Filter (ETRF) for dialysis and related therapies. J Jpn Soc Dial Ther. 2011;44:977-90.

8. The Statistical Survey Committee of the Japanese Society for Dialysis Therapy. An overview of regular dialysis treatment in Japan as of December 31, 2014 (illustrated). Tokyo: Japanese Society for Dialysis Therapy; 2015.

9. Hasegawa T, Nakai S, Masakane I, et al. Dialysis fluid endotoxin level and mortality in maintenance hemodialysis: a nationwide cohort study. Am J Kidney Dis. 2015;65:899-904.

10. ISO 13959: 2014. Water for haemodialysis and related therapies, http://www. iso.org/iso/

11. Eaton JW, Kolpin CF, Swofford HS, Kjellstrand CM, Jacob HS. Chlorinated urban water: a cause of dialysis-induced hemolytic anemia. Science. 1973;181:463-4.

12. Association of Membrane Separation Technology of Japan/Revision Committee on Dialysis water Guidebook. Guidebook for dialysis water. Tokyo: Association of Membrane Separation Technology of Japan; 2014. p. 18.
13. Japan Water Plumbing Engineering Promotion Foundation. Water supply equipment plumbing engineering guideline, revised. Tokyo: Japan Water Plumbing Engineering Promotion Foundation; 2013. p. 12. (modified in part)

14. Association of Membrane Separation Technology of Japan. Provisions for certification of modules for drinking water use. 7th ed. Tokyo: Association of Membrane Separation Technology of Japan; 2014. p. 21.

15. ISO 26722: 2014. Water treatment equipment for haemodialysis applications and related therapies, http://www.iso.org/iso/

\section{Submit your next manuscript to BioMed Central and we will help you at every step:}

- We accept pre-submission inquiries

- Our selector tool helps you to find the most relevant journal

- We provide round the clock customer support

- Convenient online submission

- Thorough peer review

- Inclusion in PubMed and all major indexing services

- Maximum visibility for your research

Submit your manuscript at www.biomedcentral.com/submit
) Biomed Central 